[4] Madeley NJ, Wing KJ, Topliss C et al. Responsiveness and validity of the SF-36, Ankle Osteoarthritis Scale, AOFAS Ankle Hindfoot Score, and Foot Function Index in end stage ankle arthritis. Foot Ankle Int 2012;33:57-63

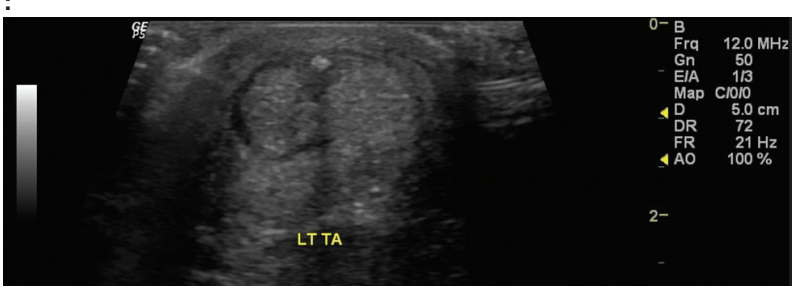

Fig (1) Ultrasound Transverse scan over left TA of male 25 squash player shows hyperechoic dot of calcification inside the tendon with acoustic shadowing before treatment.

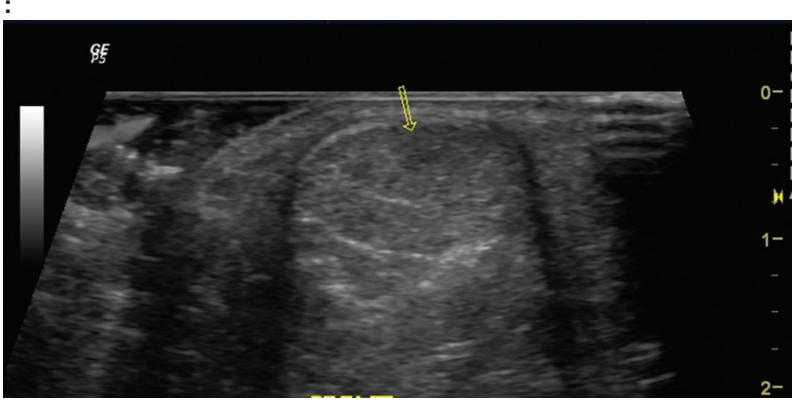

Fig(2) same patient, after 3 months of treatment with ESWT shows disappearance of calcification

Disclosure of Interests: None declared DOI: 10.1136/annrheumdis-2019-eular.4818

\section{AB0913 THE ROLE OF BISPHOSPHONATES IN THE MANAGEMENT OF SPONTANEOUS OSTEONECROSIS OF THE KNEE (SONK)}

Mark Ford, Roshan Amarasena. The Robert Jones and Agnes Hunt Orthopaedic Hospital NHS Foundation Trust, Gobowen, United Kingdom

Background: Spontaneous osteonecrosis of the knee (SONK) was first described by Ahlbäck, Bauer and Bohnein in 1968 when they identified 39 patients with radiolucent lesions of subchondral bone in the medial femoral condyle which represented a manifestation of osteonecrosis. The aetiology and pathogenesis of SONK remains unclear with possibilities including microvascular compromise, reduced bone mineral density, and mechanical disruption within the knee. The treatment compromises of conservative, medical and surgical options depending on the severity of osteonecrosis identified on imaging. Lai et al (2005) demonstrated the beneficial effect of alendronate in the prevention of early collapse of the femoral head in patients with nontraumatic osteonecrosis. However, the role of bisphosphonates in the treatment of SONK is debated and the evidence is based upon a few studies.

Objectives: To assess the evidence for the use of bisphosphonates in SONK.

Methods: A literature search was conducted to identify studies reporting the effect of bisphosphonates in the treatment of SONK and the usefulness and validity of their conclusions was subsequently assessed.

Results: We have identified one randomised controlled trial and four case series investigating the use of a bisphosphate on the clinical and radiological outcome in patients with osteonecrosis of the knee. All four case series showed improvements with bisphosphonates on patient visual analogue scale (VAS) and radiological outcome. However, the sole randomised controlled trial reported that bisphosphonates had no additional benefit over conservative measures and anti-inflammatory medications after 24 or 48 weeks both functionally and radiographically. These studies had a small number of participants and the size of the osteonecrotic lesion was either small, which traditionally is managed conservatively, or not interpreted in the context of the results.
Conclusion: The role of bisphosphonates in the treatment of SONK remains unclear. Further randomised controlled trials would be beneficial in these patients with emphasis on the symptom duration and the size of the osteonecrotic lesion.

\section{REFERENCES}

[1] Agarwala, S., Sharoff, L. and Jagani, N., 2018. Effect of zoledronic-acid and alendronate on bone oedema and pain in spontaneous osteonecrosis of the knee: a new paradigm in medical management. Revista Brasileira de Ortopedia (English Edition). Accessed via: https://www.sciencedirect. com/science/article/pii/S2255497118300089 on 31st December 2018.

[2] Breer, S., Oheim, R., Krause, M., Marshall, R.P., Amling, M. and Barven cik, F., 2013. Spontaneous osteonecrosis of the knee (SONK). Knee Surgery, Sports Traumatology, Arthroscopy, 21(2), pp.340-345

[3] Jureus, J., Lindstrand, A., Geijer, M., Roberts, D. and Tägil, M., 2012 Treatment of spontaneous osteonecrosis of the knee (SPONK) by a bisphosphonate: A prospective case series with 17 patients. Acta orthopaedica, 83(5), pp.511-514.

[4] Kraenzlin, M.E., Graf, C., Meier, C., Kraenzlin, C. and Friedrich, N.F., 2010. Possible beneficial effect of bisphosphonates in osteonecrosis of the knee. Knee surgery, sports traumatology, arthroscopy, 18(12), pp.16381644.

[5] Lai, K.A., Shen, W.J., Yang, C.Y., Shao, C.J., Hsu, J.T. and Lin, R.M. 2005. The use of alendronate to prevent early collapse of the femora head in patients with nontraumatic osteonecrosis: a randomized clinical study. JBJS, 87(10), pp.2155-2159

[6] Meier, C., Kraenzlin, C., Friederich, N.F., Wischer, T., Grize, L., Meier, C R. and Kraenzlin, M.E., 2014. Effect of ibandronate on spontaneous osteonecrosis of the knee: a randomized, double-blind, placebo-controlled trial. Osteoporosis international, 25(1), pp.359-366.

Disclosure of Interests: None declared

DOI: 10.1136/annrheumdis-2019-eular.5117

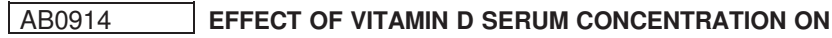 ARTRALGIA INDUCED BY ADJUVANT THERAPHY WITH AROMATASE INIBITORS IN NON METASTATIC BREAST CANCERS SURVIOVORS}

Emanuele Gotelli, Carlotta Schenone, Francesco Cattelan, Elisa Alessandri, Federica Goegan, Massimo Patanè, Massimo Ghio, Maurizio Cutolo,

Sabrina Paolino. IRCCS San Martino Polyclinic Hospital, Genoa, Italy, Research Laboratory and Academic Division of Clinical Rheumatology, Department of Internal Medicine, University of Genova, genoa, Italy

Background: Hand arthralgia is often reported by breast cancer patients treated with adjuvant hormonal therapy. Aromatase inhibitors (Als) improve survival in postmenopausal women with hormone-sensitive breast cancer but can cause joint pain and stiffness (2). Low concentration of vitamin $D$ in adults can cause musculoskeletal pain and joint discomfort (1). No data are available to date, on serum concentrations of (25-hydroxyvitamin D) $\left[25(\mathrm{OH}) \mathrm{D}_{3}\right.$ ] vitamin $\mathrm{D}$ in Al-treated patients and possible relationship with arthralgia.

Objectives: To evaluate possible correlation between different $25(\mathrm{OH}) \mathrm{D}_{3}$ serum concentrations and hand arthralgia in patients with breast cance treated with Als.

Methods: All patients that during the Als therapy develop arthralgia referred to the rheumatologist; they reported the pain following the VAS (visual analogic scale) and contemporary performed a sample blood for dosage of vitamin $\mathrm{D}$ as well as biomarkers for inflammation and autoimmunity to exclude concomitant immune/inflammatory rheumatic musculoskeletal causes.

Results: In a group of 63 women taking Als (mean age $62.3 \pm 9.8 y e a r s$; disease duration from first assumption of AIS $10.6 \pm 3.2$ months) $81 \%$ reported hand arthralgia and stiffness within the first year of follow-up; the most prevalent site of pain localization was bilateral hands (85\%) Symptom was associated with minimal increase of serum parameters of inflammation (the mean value of C-reactive protein was $7.1 \pm 3.0 \mathrm{mg}(\mathrm{L}$ (normal value $0-5$ ) but negative autoimmune profile (negative rheumatoid factors and anticitrullinated protein antibodies). The mean $25(\mathrm{OH}) \mathrm{D}_{3}$ serum concentration was $18.4 \pm 8.5 \mathrm{ng} / \mathrm{ml}$. Only $9 \%$ of women had an adequate $(\geq 30 \mathrm{ng} / \mathrm{ml})\left[25(\mathrm{OH}) \mathrm{D}_{3}\right]$ vitamin $\mathrm{D}$ serum levels, $70 \%$ were insufficient ( $>10<20 \mathrm{ng} / \mathrm{mL}$ ), and $21 \%$ were severely deficient $(<10 \mathrm{ng} / \mathrm{mL}$ ). $55 \%$ of patients started Als after chemotherapy. From the group that received Als after chemotherapy $77 \%$ patients with arthralgia were found during the first years of hormonal therapy, in the group that previously did not take chemotherapy $88 \%$ of patients referred arthralgia. There was any 
difference on vitamin $D$ serum levels between patients previously treated or not treated with chemotherapy $(17.8 \pm 7.8 \mathrm{vs} 19.3 \pm 9.7 \mathrm{p}=0.6)$. After subdivision of patients that referred hand arthralgia according to the different type of Als used: $22 \%$ have been treated with tamoxifen, $30 \%$, anastrozole and $48 \%$ letrozole. Therefore, the baseline serum vitamin D concentrations did not significantly predict arthralgia in the overall group $(P=0.70)$ or separately in the single Als group (anastrozole $(P=0.60)$ or tamoxifene $(P=0.30)$ or letrozole $(P=0.60$, respectively).

Conclusion: Vitamin D serum concentrations in women treated with Als are at lowest ranges in the majority of the patients analysed, but no apparent interference with musculoskeletal symptoms was found related to the different concentrations; the cause of arthralgia might be better related to estrogen deficiency induced by Als their self.

\section{REFERENCES}

[1] Kathryn R, et al. 2017 Ther Adv Musculoskelet Dis.9(6):131-135

[2] Hsieh KP, et al. 2014. PLoS One, 9, e87027.

Disclosure of Interests: None declared

DOI: 10.1136/annrheumdis-2019-eular.6968

\section{АВ0915 ЭФФЕКТИВНОСТЬ АКУПУНКТУРЫ ПРИ ТЕРАПЕВТИЧЕСКИХ УПРАЖНЕНИЯХ ПРИ ЛЕЧЕНИИ МИОФАСЦИАЛЬНОЙ БОЛИ В НИЖНЕЙ ЧАСТИ спины}

Evgenia Guryanova, Oleg Tichoplav. Chuvash State University, Cheboksary, Russian Federation

Background: Myofascial pain syndrome in the lower back is one of the most common diseases. At the current time, there are no ideal ways to treat this disease. Pharmacological treatments are not suitable for many patients. Regular use of painkillers and NSAIDs is associated with the risk of serious adverse reactions in patients. Using only pharmacotherapy without using non-pharmacological treatment methods is not a rational approach to treating such patients.

Acupuncture has a wide range of effective methods of combating combat syndrome that can have a quick positive effect, and, unlike drugs, this method remains safe. Therapeutic exercise is a treatment method that is able to raise the general threshold of pain sensitivity by including nonspecific adaptation mechanisms [1]. This effect develops slowly, but it acts for a very long time.

Objectives: The purpose of this study is to compare the effectiveness of acupuncture with massage in the treatment of myofascial pain in the lower back with complex treatment, including exercise.

Methods: A prospective clinical study was conducted with patients suffering from myofascial pain syndrome in the lower back, which were randomly divided into one of two groups: patients (60 cases) who received combined treatment including massage, acupuncture and exercise therapy, and patients (30 cases) of group 2 (G2) who received only massage procedures and acupuncture without medical gymnastics. They were assigned to group 1 (G1). The age composition of the G1 group of patients from 31 to 70 years. Gender composition - 22 (37\%) - women, and $38(63 \%)$ - men.

All patients received treatment 5 times a week (from Monday to Friday, excluding Saturday and Sunday), the total duration of the rehabilitation course is 10 days. The therapeutic program included the following nondrug methods of exposure: for G1, 30 minutes - an acupuncture session, 20 minutes a back massage session, and at least 45 minutes of exercises in the gymnastics hall with an instructor in physical therapy. G2 patients received similar non-drug therapy with the exception of classes in the gymnastics room. The visual-analogue scale (VAS) was used as a method of performance evaluation, which was evaluated at the beginning of the study, at the fifth, ninth and last visit to the clinic.

Results: The average time between the onset of clinical symptoms and the first day of treatment was 34.6 days. In $80 \%$ of patients, a history of pain lasted for more than 3 months. 89 patients (98\%) completed the protocol: $60(100 \%)$ in G1 and $29(97 \%)$ in G2. The average VAS score in $\mathrm{G} 1$ was 6.9 at the beginning of the study and after the tenth session it dropped to 2, 6. A significant decrease in pain was registered in the G2 group (from 6.9 at the beginning of the study to 3.3 after the tenth session). A statistically significant difference $(p<0$. 05) between different sessions was noted.

In order to assess the period of time during which the effect of treatment is maintained, all patients were asked to send a subjective assessment on the VAS scale to the attending physician after completion of treatment monthly for 12 months. When analyzing these data, it was established that the inclusion of physiotherapy exercises preserves a clear effect of therapy for 3.1 months longer than without the use of therapeutic gymnastics.

Conclusion: The results indicate high efficiency acupuncture in the treatment of myofascial pain syndrome, however, its combination with therapeutic exercises allows to better consolidate the effect and contributes to a longer remission of pain syndrome. It is necessary to establish clear criteria for inclusion in the treatment of exercise

\section{REFERENCE}

[1] Krysyuk O.B., Lutkov V.F., Smirnov G.I., Shadrin D.I. Physiotherapy and massage in the complex rehabilitation of athlete. Ministry of Sport of the Russian Federation, PF Lesgaft National State University of Physical Education, Sport and Health, St. Petersburg. St. Petersburg, 2014.

Disclosure of Interests: None declared

DOI: 10.1136/annrheumdis-2019-eular.5835

\section{AB0916 INVESTIGATION OF PAIN AND DEPRESSION IN CANCER OUTPATIENTS RECEIVING CHEMOTHERAPY}

Fulya IPEK, Vesile Yıldız Kabak, Songül Atasavun Uysal, Tulin Duger. Hacettepe University, Physiotherapy and Rehabilitation, Ankara, Turkey

Background: Cancer treatments such as chemotherapy contribute to the development of depression and pain (1). Prevalence of pain ranges from $14 \%$ to $100 \%$ and depressed symptoms occur $1-42 \%$ in cancer patients (2). The empirical evidence indicates that pain is often untreated and may induce depression in cancer patients $(1,2)$ and depression affects the management of symptoms such as pain (3). Therefore, depression and pain have interrelated effects with each other. Pain and depression in cancer patients lead to discontinuation of therapy, difficulties in controlling symptoms and negative treatment compliance (4). Studies report the need for more research on pain and depression associated with cancer treatment (2).

Objectives: The objectives of this study are to: 1) compare the depression levels of painful and painless cancer patients who received outpatient chemotherapy; and 2) investigate the relationship between pain and depression in these patients.

Methods: This study was carried out in outpatient chemotherapy unit of Hacettepe Oncology Hospital based in Ankara, the capital city of Turkey. The visual analog scale (VAS) was used to investigate if the patients may have had pain. The Brief Pain Inventory (BPI) was of help to assess the pain severity and pain interference on the function of patients while the Beck Depression Inventory (BDI) was applied to evaluate depression.

Results: The study findings are based on the outcomes of 27 cancer outpatients receiving chemotherapy. Their mean age was $56.89 \pm 11.08$ years (age range; 31-73). Almost half of the of patients had pain $(48.15 \%)$. There was a difference between the depression scores of the patients who had pain and the other patients without pain but this is not statistically significant $(p=.07)$. The depression scores of painful patients and non-painful patients were 13 and 6 , respectively. There was a moderate association between scores of pain severity and depression ( $r=0.4$ $p=0.04)$. Moreover, there was a high association between the score of depression and pain interference on function $(r=0.61, p=.016)$.

Conclusion: This study shows that pain is related with depression in cancer outpatients receiving chemotherapy. Depression may occur more frequently in patients who have experienced pain than in patients with no pain and also depression is likely to increase pain in cancer patients Therefore, the addition of emotional and psychosocial components for treatment procedures and effective pain management may have positive effects on the treatment of cancer outpatients receiving chemotherapy.

\section{REFERENCES}

[1] Kelly, Debra Lynch, et al. "Relationships Among Fatigue, Anxiety, Depression, and Pain and Health-Promoting Lifestyle Behaviors in Women With Early-Stage Breast Cancer." Cancer nursing (2019).

[2] Patrick, D. L., et al. "National Institutes of Health State-of-the-Science Conference Statement: symptom management in cancer: pain, depression, and fatigue, July 15-17, 2002." Journal of the National Cancer Institute 95.15 (2003): 1110-1117.

[3] Mercadante, Sebastiano, et al. "Symptom hyper-expression in advanced cancer patients with anxiety and depression admitted to an acute suppor tive/palliative care unit." Supportive Care in Cancer (2019): 1-8. 